\title{
Orthopedic Injuries from Video Games: A Literature Review and Implications for the Future
}

\author{
${ }^{1}$ Department of Orthopedic Surgery, Larkin Community Hospital, South Miami, FL, USA \\ ${ }^{2}$ United States Military Academy at West Point, West Point, NY, USA \\ ${ }^{3}$ American University of Antigua College of Medicine, St. Johns, Antigua and Barbuda
}

Phong Truong, $D O^{1^{*}}\left(\mathrm{D}\right.$, Long Truong, BA $\mathbb{D}$, Tuan Le, $B S^{2}(\mathbb{D}$, and Kristina Kuklova, MBA, MS

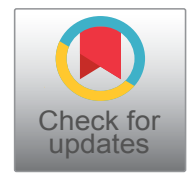

*Corresponding author: Phong Truong, DO, Department of Orthopedic Surgery, Larkin Community Hospital, 7000 SW 62nd Ave, Suite 401, South Miami, FL 33143, USA, Tel: 305-284-7500

\begin{abstract}
The video gaming industry is flourishing with billions of participants worldwide and has surpassed both the music and movie industry in revenue. An activity as ubiquitous as this brings with it the risk of injury, in particular orthopedic injury. Acute fractures and dislocations from video gaming have been reported, as well as overuse injuries such as wrist tendonitis. The repetitive motions seen in video gaming may develop over time into severe orthopedic manifestations which may require extensive therapy or invasive surgery. Such manifestations may include thumb carpometacarpal joint arthritis, carpal tunnel syndrome, trigger finger, tendonitis, rotator cuff tear, and more. This calls for a push in biomechanical research in regards to joint reactive forces of the upper extremity and how these forces could be alleviated with the introduction of more ergonomic gaming products. It also presents many opportunities for orthopedic surgeons and healthcare providers to be consultants for video gaming companies and to assist in designing said products.
\end{abstract}

\section{Keywords}

Orthopedic surgery, eSports, Video game injuries

\section{Abbreviations}

MRI: Magnetic Resonance Imaging; eSports: Electronic Sports

\section{Introduction}

The video game industry is worth more than the music and movie industry combined. Its revenue reached $\$ 152.1$ billion in 2019 and is expected to rocket towards $\$ 257$ billion by 2025 [1]. Of the estimated 2.5 billion active gamers worldwide, [2] we see that $21 \%$ are under the age of $18,38 \%$ are between the ages of 18 and 35 , and $26 \%$ are between the ages of 36 and 54 [3]. That means $85 \%$ of total gamers are under the age of 55 . The expansion of the video gaming industry brings with it the risk of possible injury. There are acute injuries from traumatic events such as falling while gaming, but there are also risks of overuse injuries from performing repetitive motions for long periods of time. In addition to acute and overuse injuries, there are concerns for long term orthopedic manifestations from many years of video gaming.

\section{Acute Injuries}

Through our literature review, multiple case reports of acute injuries related to video gaming were found. Two cases of Achilles tendon tears, a 46-year-old and a 42-year-old, have been reported $[4,5]$. Another injury occurred in an 18-year-old female after she fell playing Wii Tennis and dislocated her left patella [6]. This has been referred to as the "Wii Knee" $[6,7]$. She was treated in a cast and performed quadriceps-strengthening exercises for 6 weeks; she had no repeat dislocations [6]. Almedghio, et al. submitted a case report in regards to a 23-year-old female who had an injury to her right knee while bowling on the Nintendo Wii [8]. MRI was performed indicating a medial meniscus tear, for which she underwent arthroscopic partial medial meniscectomy [8].

There were also several cases of fracture from video

Citation: Truong P, Truong L, Le T, Kuklova K (2020) Orthopedic Injuries from Video Games: A Literature Review and Implications for the Future. Int Arch Orthop Surg 3:020. doi.org/10.23937/26434016/1710020

Accepted: August 29, 2020; Published: August 31, 2020

Copyright: (C) 2020 Truong P, et al. This is an open-access article distributed under the terms of the Creative Commons Attribution License, which permits unrestricted use, distribution, and reproduction in any medium, provided the original author and source are credited. 
gaming. A 14-year-old girl in the United Kingdom presented to the emergency department after falling off a Wii Fit balance board and was found to have a fracture at the base of her fifth metatarsal [9]. She was treated conservatively with crutches. One man sustained a clavicle fracture from playing Pokémon GO in 2016 and took to Twitter to share his radiographs [10]. Galanopoulos, et al. submitted a case report regarding a 54-year-old male that was ten-pin bowling on the Wii and hit his hand on a coffee table, resulting in a Rolando fracture at the base of his right thumb metacarpal [11]. He required open reduction and internal fixation for the injury, but subsequently regained full function within seven months [11].

\section{Overuse Injuries}

In the world of orthopedics, overuse injuries are those caused by repetitive microtrauma to the musculoskeletal system [12]. Often seen in sports, these injuries develop subtly over time. Examples of overuse injuries are tennis elbow, runner's knee, jumper's knee, little leaguer's shoulder, shin splints, and more [12]. However, with the advent of video games, a new cause of overuse injuries is emerging. Some call it "Nintendonitis", referring to the repetitive strain injuries often seen with video gaming $[13,14]$. These repetitive strains are not limited to the Nintendo Wii; computer gamers are also at risk. A recent article highlighted the experience of a pediatric hand surgeon and the increasing incidence of overuse injuries seen in her video gaming patients [15]. In particular, it mentions a 15-year-old professional eSport athlete that was diagnosed with wrist tendonitis secondary to his ten hour-a-day training schedule [15]. This injury greatly affected his ability to compete, forcing him to take a one-month break from playing; in addition to that, he was not able to return to his pre-injury level of play after taking a month off [15]. He was treated conservatively with icing, anti-inflammatory medication, ergonomic adjustments, and physical therapy [15].

\section{Future Implications}

Sports, music, and occupational injuries have given insight to the possible future orthopedic manifestations from video gaming. All of these activities include repetitive joint movements. One article suggests that physical load from sports may put women at risk for development of severe hip osteoarthrosis [16]. Another study found over half of retired elite female soccer players have osteoarthritis and meniscus tears [17]. There is also high prevalence of hip and knee osteoarthritis arthroplasty among former elite male athletes [18]. Musicians such as pianists are at increased risk of developing upper extremity nerve compression [19,20]. Occupational activities also play a role, as consistent overhead activity in painters shows high rates of rotator cuff tears $[21,22]$. Like the aforementioned activities, video gaming consists of performing repetitive motions for long periods of time. Some train for $5-14$ hours a day $[23,24]$. Over the course of many years, this can lead to potential orthopedic problems.

The future implications have potential to be monumental for orthopedic surgeons. Today's patient demographic will no longer be limited to only professional athletes, elite musicians, or adult laborers, but to the average everyday gamer which can range from children to middle-aged adults [3]. Competitive video gaming is also gaining in popularity, with many universities adding intercollegiate eSports departments $[25,26]$. Injuries as a result of gaming are starting to become more prevalent as the competitive eSports scene and live stream community continue to grow. The repetitive motions performed in gaming, especially fine motor movements may develop over time into symptomatic orthopedic manifestations potentially requiring extensive rehabilitation or invasive surgery [27]. One study reports pain in $39 \%$ of computer and video gamers, with majority of it being back and upper extremity pain [28]. For many years, video games were played with one's hands; but with the advent of the Nintendo Wii and virtual reality gaming systems, the entire upper extremity is involved. That introduces more potential for injury. In addition to the acute fracture and dislocations, there will be an increased need for surgical intervention of thumb carpometacarpal joint arthritis, carpal tunnel syndrome, trigger finger, tendonitis, rotator cuff tear, and more.

The upside is that it presents many opportunities for orthopedic surgeons and healthcare providers to be consultants for video gaming companies like Sony, Nintendo, and Microsoft in research and development of more ergonomic consumer products such as video game controllers, keyboards, and chairs. Medical accessories such as braces and gloves are being designed and further specialized in efforts of reducing and treating these injuries [29]. For example, one professional video gamer sustained a wrist injury at 21-years-old that prevented him from playing for over a year [30]. Ultimately, it was a more ergonomic controller that allowed him to compete again [30]. Orthopedic surgeons have an opportunity to engage with the professional eSports community to provide their expertise; preventing injury and getting players back in the game.

To aid in the development of these products, more research ought to be performed. In particular, biomechanical studies comparing joint reactive forces on specific joints of the upper extremity and how these forces could be alleviated with the introduction of more ergonomic products. Testing current ergonomic products on the market could provide insight on the development of new designs.

\section{Conclusion}

As the video gaming industry continues to grow, orthopedic surgeons ought to be more aware of the po- 
tential injuries that may accompany it. Acute fractures and dislocations as well as long-term manifestations such as carpal tunnel syndrome are possible. This presents unique opportunities for orthopedic surgeons to be greatly involved in the video gaming scene. In addition to treating esport athletes and casual gamers, there is new opportunity to get involved in product design to improve ergonomics and minimize future injuries. Lastly, more research is required in the field of video gaming and orthopedic injury, specifically biomechanical research related to joint reactive forces in the upper extremity.

\section{Conflicts of Interest}

We declare that we have no conflicts of interest in the authorship or publication of this contribution.

\section{Author Contribution Statement}

Authors Phong Truong, Long Truong, Tuan Le, and Kristina Kuklova contributed to the conception, design, and drafting of the work; approved the final version to be published; and agreed to be accountable for all aspects of the work.

\section{References}

1. Gaming Market - Growth, Trends, Forecasts (2020 - 2025).

2. (2019) The Global Games Market Will Generate \$152.1 Billion in 2019 as the U.S. Overtakes China as the Biggest Market. Newzoo.

3. https://www.statista.com/statistics/189582/age-of-us-video-game-players-since-2010/

4. Singh R, Manoharan G, Moores TS, Patel A (2014) Nintendo Wii related Achilles tendon rupture: First reported case and literature review of motion sensing video game injuries.

5. Beddy P, Dunne R, De Blacam C (2009) Achilles wiiitis. AJR Am J Roentgenol 192: W79.

6. Hirpara KM, Abouazza OA (2008) The "Wii Knee": A case of patellar dislocation secondary to computer video games. Inj Extra 39: 86-87.

7. Robinson RJ, Barron DA, Grainger AJ, Venkatesh R (2008) Wii knee. Emerg Radiol 15: 255-257.

8. Almedghio SM, Shablahidis O, Rennie W, Ashford RU (2009) Wii knee revisited: Meniscal injury from 10-pin bowling. BMJ Case Rep 2009: bcr1120081189.

9. Eley KA (2010) Wii Fracture. N Engl J Med 362: 473-474.

10. Doctors reveal the 5 most common Pokemon Go injuries and how to avoid them. Daily Mail Online.

11. Galanopoulos I, Garlapati AK, Ashwood N, Kitsis C (2012) A Wii virtual activity severe thumb metacarpal injury. BMJ Case Rep 2012: bcr2012006967.

12. (2019) Overuse injuries. Orthopedic Associates.
13. Macgregor D (2000) Nintendonitis? A case report of repetitive strain injury in a child as a result of playing computer games. Scott Med J 45: 150.

14. Siegel IM (1991) Nintendonitis. Orthopedics 14: 745.

15. (2020) eSports Gamers Emerge as the Newest Orthopaedic Patient.

16. Vingård E, Alfredsson L, Malchau H (1998) Osteoarthrosis of the hip in women and its relationship to physical load from sports activities. Am J Sports Med 26: 78-82.

17. Prien A, Boudabous $S$, Junge A, Verhagen E, Delattre BMA, et al. (2020) Every second retired elite female football player has MRI evidence of knee osteoarthritis before age 50 years: A cross-sectional study of clinical and MRI outcomes. Knee Surg Sport Traumatol Arthrosc 28: 353-362.

18. Tveit M, Rosengren BE, Nilsson JÅ, Karlsson MK (2012) Former male elite athletes have a higher prevalence of osteoarthritis and arthroplasty in the hip and knee than expected. Am J Sports Med 40: 527-533.

19. Gohl AP, Clayton SZ, Strickland K, Bufford YD, Halle JS, et al. (2006) Median and ulnar neuropathies in university pianists. Med Probl Perform Art 21: 17-25.

20. Mhanna C, Marquardt TL, Li ZM (2016) Adaptation of the transverse carpal ligament associated with repetitive hand use in pianists. In: Zhao C. PLoS One 11: e0150174.

21. Loew M, Doustdar S, Drath C, Weber MA, Bruckner T, et al. (2019) Could long-term overhead load in painters be associated with rotator cuff lesions? A pilot study. PLoS One 14: e0213824.

22. Shahady EJ, Paull W, Smith S (2005) Shoulder pain that prevents a painter from working. Consultant 45: 553-557.

23. Hollist KE (2015) Time to be grown-ups about video gaming: The Rising eSports Industry and the need for regulation. Ariz Law Rev 57.

24. Kari T, Karhulahti VM (2016) Do e-athletes move? A study on training and physical exercise in elite e-sports. Int $\mathrm{J}$ Gaming Comput Simulations 8: 53-66.

25. Keiper MC, Manning RD, Jenny S, Olrich T, Croft C (2017) No reason to LoL at LoL: The addition of esports to intercollegiate athletic departments. J Study Sport Athletes Educ 11: $143-160$.

26. Funk DC, Pizzo AD, Baker BJ (2018) eSport management: Embracing eSport education and research opportunities. Sport Manag Rev 21: 7-13.

27. Booth-Malnack K (2019) The biological basis of nervous tissue repetitive strain injuries in eSports competitors. Honor Thesis.

28. Zapata AL, Moraes AJP, Leone C, Doria-Filho U, Silva CAA (2006) Pain and musculoskeletal pain syndromes related to computer and video game use in adolescents. Eur J Pediatr 165: 408-414.

29. Piper B (2017) Design and validation of a smart brace; Wearable technology for carpal tunnel syndrome.

30. Khan I (2017) Control Freak: How an injured esports athlete got back into the game. Capstones. 